\title{
Pengalaman Komunikasi Lintas Budaya Mahasiswa Undergraduate Indonesia di Belanda
}

\author{
Daulat Ilmi Maldani*, Erik Setiawan \\ Prodi Public Relation, Fakultas Ilmu Komunikasi, Universitas Islam \\ Bandung, Indonesia. \\ *daulatilmi@gmail.com, erik.setiawan@unisba.ac.id
}

\begin{abstract}
The Netherlands is one of the countries which is famous for the best quality of education, no wonder why many people from all over the world are competing to continue their studies in the Netherlands. This is supported by the presence of advanced technology and excellent human resources quality. In addition, there are various benefits such as extensive experience and world wide networking which are also other things to consider. However, communication barriers and the phenomenon of shock culture often occur due to differences in culture and habits in new places. This study used a qualitative method with a phenomenological study approach and an interactionist paradigm. The objectives of this study are 1) to find out how the crosscultural communication experience of Indonesian undergraduate students in the Netherlands. and 2) to understand the meaning of cross-cultural communication experienced by Indonesian undergraduate students in the Netherlands. In this research, the theory used is Cross-Cultural Communication which is fundamental to Speech Code Theory and Face Negotiation Theory. The results of this study illustrate that the experiences contained are classified into three parts, namely cross-cultural communication experiences, self-experiences, and experiences with the environment. There is also a meaning that is formed from Indonesian undergraduate students in carrying out the study process in the Netherlands as a way to achieve the desired goals.
\end{abstract}

Keywords: Cross-Cultural Communication; Speech Codes; Study Abroad; Undergraduate Program; International Studies

Abstrak. Belanda merupakan salah satu negara yang terkenal dengan kualitas pendidikan yang terbaik, tidak heran mengapa banyak masyarakat dari berbagai penjuru dunia berlomba-lomba untuk melanjutkan studinya di Belanda. Hal ini didukung dengan adanya teknologi yang maju dan sumber daya manusia yang baik. Selain itu, terdapat berbagai manfaat seperti pengalaman dan relasi yang luas juga menjadi hal lain yang dipertimbangkan. Namun, adanya hambatan komunikasi dan fenomena gegar budaya sering kali terjadi. Penelitian ini menggunakan metode kualitatif dengan pendekatan studi fenomenologi dan paradigma interaksionis. Tujuan dari penelitian ini yaitu 1) untuk mengetahui bagaimana pengalaman komunikasi lintas budaya mahasiswa undergraduate Indonesia di Belanda. dan 2) untuk memahami bagaimana makna pada komunikasi lintas budaya yang dialami mahasiswa undergraduate Indonesia di Belanda. Dalam penelitian ini, teori yang digunakan yaitu Komunikasi Lintas Budaya yang mendasar pada Speech Code Theory dan Face Negotiation Theory. Hasil dari penelitian ini menggambarkan bahwa pengalaman yang terdapat diklasifikasi kedalam tiga bagian yaitu pengalaman komunikasi lintas budaya, pengalaman diri sendiri, dan pengalaman dengan lingkungan. Lalu, adanya makna yang terbentuk dari mahasiswa undergraduate Indonesia dalam menjalankan proses studi di Belanda sebagai cara untuk meraih cita-cita yang diinginkan.

Kata Kunci: Komunikasi Lintas Budaya; Speech Codes; Belajar di Luar Negeri; Pendidikan Sarjana; Mahasiswa Internasional 


\section{A. Pendahuluan}

Belanda merupakan salah satu negara yang berada di kawasan Eropa Barat. Melihat dari kondisi geografis kawasan Belanda yang berada di dekat perairan, mulai dari laut hingga banyaknya bendungan dan sungai yang menjadikan daya tarik negara ini. Selain itu, dari sisi teknologi yang sudah maju dan sumber daya manusia yang berkualitas pun menjadi salah satu kelebihan dari negara ini, sehingga kita bisa mengetahui bahwa dengan luas negara yang tidak begitu besar, namun mereka tetap mengoptimalisasikan peluang dan kesempatan yang ada agar tetap bersaing secara global.

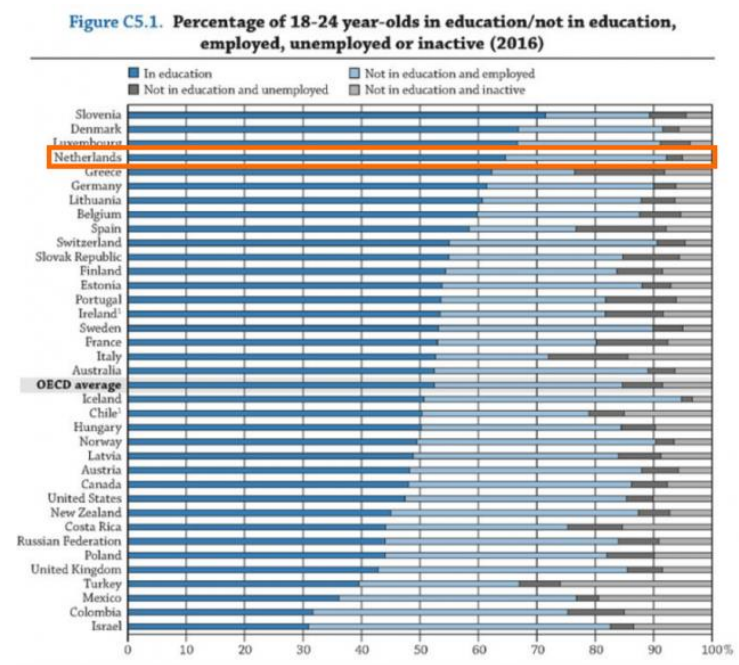

Gambar 1. Percentage of 18-24-year-olds in education/not education, employed, unemployed or inactive (2016)

Sumber: Learn Like Dutch, International Research 2016

Sistem pendidikan yang baik inilah yang membuat masyarakat dari berbagai negara di dunia rela memberanikan dirinya untuk melanjutkan studi di Belanda. Seperti yang dibuktikan oleh survey tersebut bahwa dari tahun ke tahun jumlah mahasiswa yang melanjutkan studi di Belanda ini terus meningkat. Mulai dari negara-negara European Economic Area (EEA), negara di Eropa namun non EEA, hingga negara-negara luar Eropa. Hal tersebut juga tentu membuktikan bahwa Belanda terus meningkatkan kualitas pendidikannya seiring dengan terus meningkatnya jumlah mahasiswa dari berbagai wilayah di dunia.

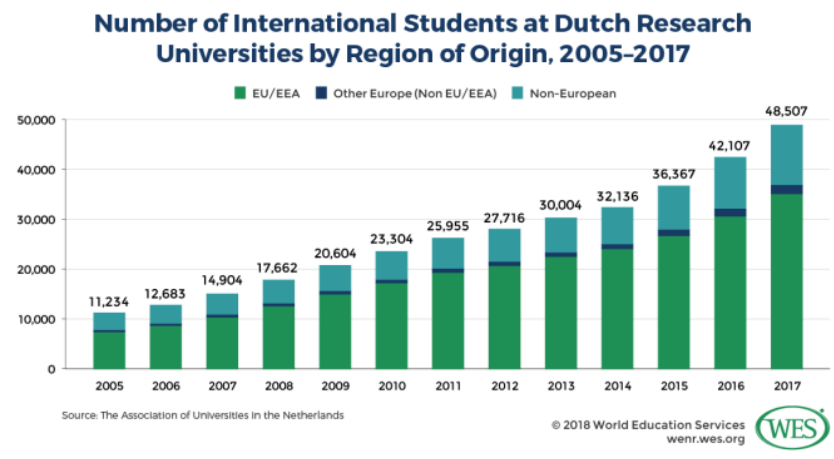

Gambar 2. Number of International Student at Dutch Research Universities by Religion of Origin 2005-2017

Sumber: World Education Services 2018

Sistem pendidikan yang baik inilah yang membuat masyarakat dari berbagai negara di dunia rela memberanikan dirinya untuk melanjutkan studi di Belanda. Seperti yang dibuktikan oleh survey tersebut bahwa dari tahun ke tahun jumlah mahasiswa yang melanjutkan studi di Belanda ini terus meningkat. Mulai dari negara-negara European Economic Area (EEA), negara di Eropa namun non EEA, hingga negara-negara luar Eropa. Hal tersebut juga tentu 
membuktikan bahwa Belanda terus meningkatkan kualitas pendidikannya seiring dengan terus meningkatnya jumlah mahasiswa dari berbagai wilayah di dunia.

Munculnya anggapan bahwa jika dilihat dari segi kualitas hingga kuantitas, perguruan tinggi di luar negeri lebih memadai di banding perguruan tinggi di Indonesia. Hal ini dibuktikan dengan penelitian yang dilakukan oleh Institute of International Education (2016) yang menyatakan bahwa "Studying abroad, especially in the case of foreign students coming to the United States (U.S.), has become increasingly popular in recent decades. In the 2015-2016 academic year, over 300,000 new international students enrolled in American higher education". Dengan ini dapat dikatakan bahwa Amerika Serikat memiliki fasilitas yang lebih memadai sehingga mahasiswa dari berbagai negara berbondong-bondong untuk melanjutkan pendidikan ke Amerika Serikat.

"Students experienced liminality in this space and the process of learning was triggered by disjuncture. Students struggled to make sense of troublesome experiences, and remained in a stuck place until resolution of troublesome-ness enabled students to cross a threshold into understanding." (Morgan, 2019) Pengalaman tersebut menunjukkan bahwa siswa yang memilih untuk melanjutkan studi di luar negeri memiliki tantangan dan problematika yang lebih tinggi dibandingkan di negara sendiri.

Pada penelitian yang dilakukan oleh Niam (2009) dapat dinyatakan bahwa kesulitan lain yang sering dialami mahasiswa Indonesia ketika tinggal di luar negeri untuk pertama kalinya yaitu adanya perbedaan pada aspek bahasa dan kebudayaan. Namun dalam beradaptasi, bahasa verbal bukan merupakan satu-satunya hal yang dibutuhkan, melainkan bahasa non-verbal juga menjadi hal yang sangat penting. Hal ini tentunya dikarenakan beragamnya pemaknaan di setiap budaya pada aspek komunikasi non-verbal. Inilah mengapa, apabila isyarat-isyarat komunikasi non-verbal tidak dipelajari oleh pendatang baru maka kesalahpahaman akan terjadi. Inilah mengapa pentingnya mahasiswa sebagai pendatang baru perlu untuk mempelajari pemaknaan komunikasi non-verbal secara mendalam.

Selain adanya fakta bahwa hambatan dan tantangan sering terjadi pada studi di luar negeri, manfaat dan pengalaman menyenangkan pun tidak dipungkiri untuk sering dialami oleh mereka. Seperti halnya pada penelitian Adler (2013) yang menyatakan bahwa "Of course, such intercultural experiences can bring many benefits, such as cultural learning and personal growth through cross-cultural adjustment". Tidak hanya itu, Smith \& Khawaja (2011) juga mengungkapkan bahwa "However they can also bring great challenges for international students, as they leave their familiar world behind, and try to adjust to a new physical, cultural, and linguistic location". Hal ini menunjukkan bahwa mahasiswa yang belajar di luar negeri tentunya memiliki berbagai keuntungan yang bermanfaat untuk tahap kehidupannya yang lebih tinggi. Karena seperti yang kita ketahui bahwa "experience is the best teacher."

Berdasarkan latar belakang yang telah diuraikan, maka perumusan masalah dalam penelitian ini sebagai berikut: "Bagaimana pengalaman komunikasi lintas budaya mahasiswa undergraduate Indonesia di Belanda?". Selanjutnya, tujuan dalam penelitian ini diuraikan dalam pokok-pokok sebagai berikut:

1. Untuk mengetahui pengalaman komunikasi lintas budaya mahasiswa undergraduate Indonesia di Belanda.

2. Untuk memahami makna yang terdapat pada pengalaman komunikasi lintas budaya mahasiswa undergraduate Indonesia di Belanda.

\section{B. Metodologi Penelitian}

Metode yang digunakan pada penelitian ini adalah penelitian kualitatif. Peneliti ingin mengetahui pengalaman komunikasi lintas budaya mahasiswa undergraduate Indonesia di Belanda. Menurut Sukmadinata (2011: 60) "Penelitian kualitatif merupakan penelitian yang ditujukan untuk mendeskripsikan dan menganalisis fenomena, peristiwa, aktivitas sosial, sikap, kepercayaan, persepsi, pemikiran orang secara individual". Kemudian Creswell (2014) mendefinisikan "Penelitian kualitatif sebagai sebuah penelitian untuk memahami masalah sosial atau masalah manusia berdasarkan pada penciptaan gambar holistik yang dibentuk dengan kata- 
kata, melaporkan pandangan informan secara terperinci, dan disusun dalam sebuah latar ilmiah".

Peneliti memilih pendekatan fenomenologi Schutz karena disesuaikan dengan judul yang diangkat peneliti untuk mengetahui tipikasi. Konsep tipikasi Schutz sendiri merupakan perpaduan terhadap pemikiran Weber dan Husserl. Adapun jenis tipikasi tergantung pada orang yang membuatnya, Schutz pun menekankan jenis tipikasi didasarkan atas kesamaan tujuan dan struktur yang relevan dengan tujuan peneltian. Kuswarno (2009: 39) menyimpulkan "singkatnya, tipikasi menyediakan seperangkat alat identifikasi, klasifikasi, dan model perbandingan dari tindakan dan interaksi sosial. Dengan menggunakan kriteria yang telah didefinisikan untuk penempatan fenomena ke dalam tipe-tipe khusus".

Menurut Smith \& Eatough (2017) tidak terdapat adanya jawaban yang tepat atas pertanyaan berapa jumlah sampel yang dibutuhkan dalam penelitian fenomenologis dikarenakan jumlah subjek tergantung pada beberapa faktor yaitu: tingkat komitmen dalam analisis dan pelaporan, kekayaan data, dan kendala yang dihadapi. Namun, 5-6 partisipan terkadang direkomendasikan sebagai jumlah sampel yang wajar (Smith \& Eatough, 2017).

Inilah mengapa penulis memilih tujuh mahasiswa undergraduate Indonesia yang berhasil direkrut untuk berpartisipasi dalam penelitian ini dengan kriteria sejumlah mahasiswa tersebut berasal dari Indonesia dan telah menjalankan studi di Belanda selama minimal dua tahun. Hal ini dikarenakan dalam kurun waktu tersebut, dapat diketahui bahwa pengalaman yang dialami oleh mereka dapat beragam sehingga dapat menjawab seluruh pertanyaan penulis dengan lengkap.

Objek penelitian adalah variabel penelitian yaitu hal yang merupakan inti dari problematika penelitian, Arikunto (dalam Fitrah dan Lutfiyah 2017:154). Dalam penelitian ini, objek penelitiannya yaitu pengalaman komunikasi lintas budaya serta makna yang terdapat dalam proses komunikasi lintas budaya yang dialami oleh mahasiswa undergraduate Indonesia selama menjalankan studinya di Belanda.

Teknik pengumpulan data merupakan cara atau teknik yang dapat digunakan peneliti untuk mengumpulkan data (Kriyantono, Rakhmat; 2016:95). Menurut Sugiyono (2014:225), pengumpulan data pada penelitian dapat diperoleh dengan berbagai cara, diantaranya: observasi, wawancara, dokumentasi, dan triangulasi. Teknik pengumpulan data yang digunakan peneliti dalam penelitian ini yaitu; observasi, wawancara, dan dokumentasi.

Data-data yang sudah didapat dan dikumpulkan, tahap selanjutnya adalah pengujian terhadap keabsahan data sehingga benar-benar sesuai dengan tujuan dan maksud penelitian, lalu agar data yang telah diperoleh mempunyai tingkat keabsahan yang baik, maka peneliti menggunakan teknik triangulasi, Moleong (2005:330) "Triangulasi adalah teknik pemeriksaan keabsahan data yang memanfaatkan sesuatu yang lain. Di luar data itu untuk pengecekan atau sebagai pembanding terhadap data itu".Pada penelitian ini, peneliti melakukan pengecekan keabsahan data melalui triangulasi sumber. Menurut Sugiyono (2017: 330) triangulasi sumber berarti untuk suatu teknik dalam mendapatkan data dari sumber yang berbeda-beda namun menggunakan teknik yang sama yang bertujuan untuk mendapatkan sudut pandang yang berbeda dari masing-masing perolehan data. 


\section{Hasil dan Pembahasan}

\section{Pernyataan-Pernyataan Mengenai "Komunikasi Lintas Budaya di Belanda"}

\begin{tabular}{|c|c|c|c|}
\hline No & Pernyataan & & \\
\hline 1 & $\begin{array}{l}\text { Orang Belanda kalo ngomong nada } \\
\text { suaranya lebih tinggi. }\end{array}$ & 11 & $\begin{array}{l}\text { Mengkomunikasikan sesuatu sejelas } \\
\text { mungkin agar dimengerti oleh } \\
\text { komunikan. }\end{array}$ \\
\hline 2 & $\begin{array}{l}\text { Kadang susah ngertiin apa yang orang } \\
\text { Belanda omongin. }\end{array}$ & 12 & $\begin{array}{l}\text { Saling menghargai akan perbedaan yang } \\
\text { dimiliki. }\end{array}$ \\
\hline 3 & $\begin{array}{l}\text { Untungnya } 90 \% \text { masyarakat Belanda } \\
\text { menguasai bahasa Inggris. }\end{array}$ & 13 & $\begin{array}{l}\text { Orang Belanda rata-rata ramah dan } \\
\text { friendly. }\end{array}$ \\
\hline 4 & $\begin{array}{l}\text { Kalo ngobrol sama orang Belanda harus } \\
\text { mikir dulu. }\end{array}$ & 14 & $\begin{array}{l}\text { Work-life balance menjadi junjungan } \\
\text { orang Belanda. }\end{array}$ \\
\hline 5 & $\begin{array}{l}\text { Sempet kaget pas pertama dateng ke } \\
\text { Belanda. }\end{array}$ & 15 & $\begin{array}{l}\text { Memahami bahwa masyarakat Belanda } \\
\text { mengutamakan kejujuran saat } \\
\text { berkomunikasi. }\end{array}$ \\
\hline 6 & $\begin{array}{l}\text { Jadi sadar kalo orang Belanda lebih } \\
\text { organized. }\end{array}$ & 16 & $\begin{array}{l}\text { Hambatan dalam berkomunikasi } \\
\text { seringkali terjadi. }\end{array}$ \\
\hline 7 & $\begin{array}{l}\text { Kurang terbiasa sama kebiasaan kiss 3x di } \\
\text { Belanda. }\end{array}$ & 17 & $\begin{array}{l}\text { Membiasakan diri untuk berkomunikasi } \\
\text { menggunakan bahasa asing. }\end{array}$ \\
\hline 8 & $\begin{array}{l}\text { Beda sama di Indo yang suka basa-basi, } \\
\text { di Belanda lebih to the point. }\end{array}$ & 18 & $\begin{array}{l}\text { Bertemu orang-orang dengan } \\
\text { karakteristik yang beragam. }\end{array}$ \\
\hline 9 & $\begin{array}{l}\text { Pengulangan kata dalam percakapan itu } \\
\text { penting kalo ada yang kurang dimengerti. }\end{array}$ & 19 & $\begin{array}{l}\text { Aspek non verbal seringkali menjadi } \\
\text { pendukung dalam proses komunikasi. }\end{array}$ \\
\hline 10 & $\begin{array}{l}\text { Salut sama budaya orang Belanda yang } \\
\text { tepat waktu. }\end{array}$ & 20 & $\begin{array}{l}\text { Dapat belajar banyak hal dari proses } \\
\text { komunikasi yang dijalankan di Belanda. }\end{array}$ \\
\hline
\end{tabular}

Kata Kunci: Nada suara tinggi, Sulit mengerti, Bahasa Inggris, Kaget, Organized, Kiss 3x, To the point, Pengulangan kata, Tepat waktu, Komunikasi yang jelas, Saling menghargai, Ramah, Work-life balance, Kejujuran, Hambatan komunikasi, Bahasa asing, Beragam karakteristik, Non-verbal communication, Belajar

Keterangan: Item-item pernyataan yang dicetak miring merupakan pernyatan deskripsi struktural, sedangkan yang dicetak normal adalah pernyataan deskripsi tekstural.

\section{Makna yang Terbentuk dari Pertanyaan-Pertanyaan Mengenai "Komunikasi Lintas Budaya} di Belanda"

\begin{tabular}{ll}
\hline No & \multicolumn{1}{c}{ Makna } \\
\hline 1 & $\begin{array}{l}\text { Penggunaan bahasa Inggris sebagai bahasa kedua di Belanda merupakan salah satu hal yang } \\
\text { mempermudah proses komunikasi. }\end{array}$ \\
2 & $\begin{array}{l}\text { Sebelum menyampaikan sesuatu, mahasiswa sebagai komunikan harus melakukan proses } \\
\text { komunikasi intrapersonal terlebih dahulu. }\end{array}$ \\
3 & $\begin{array}{l}\text { Adanya tanda-tanda non verbal juga mempengaruhi lancar tidaknya sebuah proses komunikasi. } \\
\text { Kebiasaan orang Belanda dalam menyapa yaitu kiss 3x terkadang membuat sebagian mahasiswa }\end{array}$ \\
5 & $\begin{array}{l}\text { Indonesia kurang nyaman. } \\
\text { Orang Belanda yang menyampaikan segala sesuatu dengan straight forward sangat berbeda } \\
\text { dengan orang Indonesia yang gemar basa-basi. }\end{array}$ \\
6 & $\begin{array}{l}\text { Pengulangan kata/kalimat merupakan salah satu cara efektif dalam mengatasi masalah } \\
\text { miscommunication/ misunderstanding. }\end{array}$ \\
Mempelajari bahasa Belanda juga merupakan salah satu cara agar melebur secara kultural \\
dalam proses komunikasi.
\end{tabular}




\section{Pengalaman Komunikasi Lintas Budaya Mahasiswa Undergraduate Indonesia di Belanda}

Dalam penelitian ini penulis memaparkan hasil penelitian yang berkaitan dengan hal-hal yang dialami oleh mahasiswa undergraduate Indonesia selama menjalankan pendidikannya di Belanda dan penulis juga mengklasifikasi pengalaman mahasiswa tersebut ke dalam dua bagian yaitu; pengalaman komunikasi, pengalaman dengan lingkungan, serta pengalaman dengan diri sendiri. Menurut Hafiar (dalam Nurtyasrini dan Hafiar, 2016:222) "Pengalaman komunikasi dapat dihasilkan dari interaksi antar individu yang melibatkan proses berbagi makna melalui simbol tertentu yang disebut pesan." Berdasarkan sudut pandang fenomenologis, pengalaman komunikasi lintas budaya mahasiswa undergraduate Indonesia dapat dilihat dari pengalaman komunikasi dan pengalaman dengan lingkungan yang baru. Hal ini dikarenakan kedua hal tersebut merupakan dua hal yang mencolok setelah diadakannya proses wawancara dengan para informan.

Kegiatan komunikasi yang dilakukan tentunya memiliki tujuan tertentu. Tujuan yang didefinisikan di sini mengacu pada hasil yang diharapkan oleh pelaku komunikasi. Secara umum, menurut Wilbur Schramm (dalam Sendjaja: 8), "Tujuan komunikasi dapat dilihat dari dua perspektif kepentingan, yakni: kepentingan sumber atau pengirim atau komunikator dan kepentingan penerima atau komunikan." Dengan demikian, maka tujuan komunikasi yang ingin dicapai oleh mahasiswa undergraduate Indonesia adalah sampainya informasi atau pesan dengan baik dan akurat kepada masyarakat di Belanda.

Studi komunikasi lintas budaya ini membicarakan tentang perasamaan-persamaan maupun perbedaan karakteristik kebudayaan antara pelaku-pelaku komunikasi, namun titik perhatian utamanya adalah proses komunikasi antara individu-individu atau kelompokkelompok yang berbeda kebudayaan, yang mencoba untuk saling berinteraksi. Maka konsep terpenting dalam studi ini adalah menyangkut adanya "kontak" dan "komunikasi" antar pelakupelaku komunikasi. Dari pengalaman komunikasi tersebut, dibuatlah sebuah model komunikasi lintas budaya yang dialami oleh mahasiswa undergraduate Indonesia di Belanda. Sebelumnya, menurut Deddy Mulyana (2001:121) model merupakan sebuah representatif dari suatu fenomena baik yang bersifat nyata maupun abstrak dengan menonjolkan unsur-unsur terpenting dari fenomena tersebut, namun model bukanlah fenomena itu sendiri. Jika dikaitkan dengan fenomena komunikasi, Sereno dan Mortensen (dalam Mulyana, 2001:121) mendefinisikan model komunikasi lintas budaya sebagai deskripsi ideal mengenai apa yang dibutuhkan untuk berlangsungnya proses komunikasi.

Dalam hal ini, sebuah model komunikasi lintas budaya yang digambarkan oleh Gudykunst dan Kim (1997:33) menunjukkan bahwa proses pertukaran pesan melalui sandi dalam interaksi antar individu dengan budaya yang berbeda nyatanya dipengaruhi oleh filterfilter konseptual yang terdiri dari, hal-hal berikut ini yaitu:

1. Faktor budaya, dalam hal ini berhubungan dengan nilai, norma dan aturan yang mempengaruhi perilaku komunikasi manusia yang meliputi pandangan dunia yaitu agama, bahasa, serta sikap terhadap orang lain yang dipengaruhi oleh budaya individu atau budaya kolektif.

2. Faktor sosiobudaya, hal ini bersangkutan dengan proses penataan sosial (social ordering process) yang berkembang berdasarkan interaksi dengan seorang komunikan ketika pola-pola perilaku menjadi konsisten dengan berjalannya waktu, misalnya pada pola outgroup dan ingroup, konsep diri, ekspektasi peran, dan defenisi hubungan antarpribadi.

3. Faktor psikobudaya, yang mencakup proses penataan pribadi (personal ordering process) yang memberi stabilitas pada proses psikologis seseorang dalam menjalankan komunikasi, misalnya: stereotip, etnosentrisme dan prasangka.

4. Faktor lingkungan yang meliputi: lingkungan fisik atau wilayah komunikasi, lingkungan situasi, serta kondisi dan tujuan interaksi, lingkungan aturan dan norma sosial yang menjadi aturan main sosial, lingkungan psikologi meliputi persepsi tentang kebebasan pribadi, penggunaan waktu dan interaksi lingkungan yang potensial. 


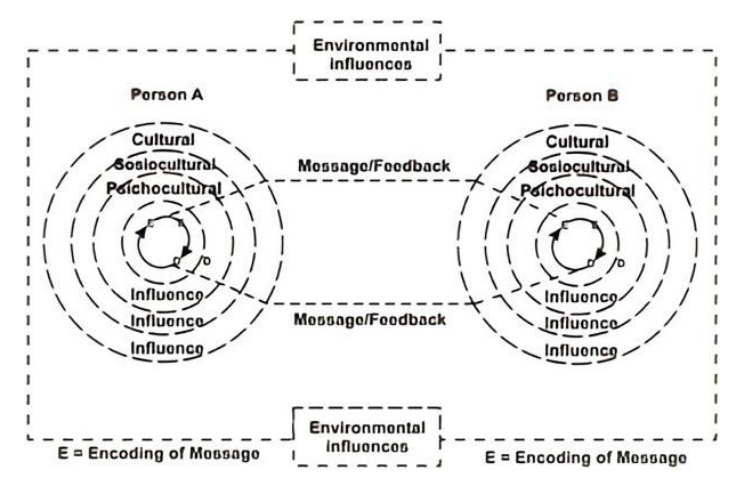

Gambar 3. Model komunikasi lintas budaya William Gudykunst\&Young Yun Kim

Dalam proses pelaksanaan komunikasi lintas budaya di Belanda, ketujuh informan menunjukkan bahwa hal-hal yang dilakukan dalam menyeleksi, mengevaluasi gaya berbicara di lingkungan Belanda yaitu dengan memperhatikan terlebih dahulu bagaimana mereka berbicara dengan gayanya, lebih ke arah manakah gaya berbicara tersebut. Kemudian dengan melihat dan merasakan gaya berbicara juga merupakan cara dalam proses menyeleksi gaya berbicara, hal ini bertujuan agar tidak semua hal yang ditemukan di Belanda khususnya dalam proses gaya berbicara ini tidak diterima secara seutuhnya. Karena seperti yang kita ketahui bahwa terdapat baik dan buruknya dari setiap hal. Tentunya dengan adanya proses evaluasi gaya berbicara juga membuat mereka dapat menyikapi bagaimana hal yang mereka hadapi.

Hafied Cangara (2015) mendefinisikan komunikasi intrapersonal sebagai proses komunikasi yang terjadi didalam diri seseorang atau dalam artian yaitu proses berkomunikasi dengan diri sendiri. Ketujuh informan menyatakan bahwa dengan adanya proses komunikasi intrapersonal maka mereka dapat lebih berhati-hati dalam berkomunikasi, tentunya dengan memikirkan dan menentukan kata-kata yang akan disampaikan kepada lawan bicara yang bertujuan agar pesan yang ingin disampaikan dapat dimengerti oleh lawan bicara. Hal ini juga perlu pemikiran secara matang, karena pada dasarnya terdapat perbedaan bahasa yang digunakan antara di Indonesia dan di Belanda.

Tidak hanya itu, dalam perbedaan dan perbandingan antara gaya berbicara budaya Indonesia dan Belanda juga terletak pada bagaimana satu sama lain menyampaikan pesan. Dalam hal ini, kekhasan speech code yang dimiliki orang Belanda menurut ketujuh informan adalah gaya berbicaranya yang to the point dan kecepatan berbicara mereka yang terlampau cepat. Kedua aspek tersebut menimbulkan culture shock yang dimana dalam budaya Indonesia sendiri, mereka terbiasa untuk berbicara dengan diawali basa-basi dan rasa sungkan yang cukup tinggi sehingga terkadang ketujuh informan merasa bahwa orang-orang Belanda itu cukup rude.

Dengan kekhasan berbicaranya yang to the point, membuat orang Belanda terbiasa untuk berbicara dengan kecepatan yang terlampau cepat. Sehingga ketujuh informan terkadang merasa kesulitan untuk dapat memahami apa yang dimaksud orang Belanda tersebut. Namun, seiring berjalannya waktu dan semakin seringnya mereka melihat dan mendengar bagaimana orang Belanda berkomunikasi, membuat ketujuh informan secara tidak sadar meniru dan menerapkan speech code dari orang Belanda itu sendiri. Beberapa informan mengakui kini gaya berbicara mereka lebih to the point dengan kecepatan berbicara yang menjadi cukup cepat. Penyamaan terhadap subtansi speech code seperti logat, kecepatan, intonasi, dan dialek bahasa menjadi tolak ukur peserta komunikasi. Konvergensi tersebut membutuhkan keterbukaan sikap dalam diri informan untuk berusaha menyesuaikan agar tidak terjadinya miscommunication. Hal tersebut disebabkan oleh setiap budaya dalam suatu negara memiliki speech code sendiri yang asing bagi orang luar. Setiap kebudayaan termasuk simbol, makna, tempat, dan aturan tentang perilaku komunikatif. Kode-kode tersebut berbeda dalam hal tertentu seperti kata-kata, makna, tempat, dan aturan tentang perilaku komunikatif. Kekhasan speech code dapat di identifikasikan lewat logat, kecepatan berbicara, imbuhan partikel, mimik, serta intonasi dalam pengucapan seseorang ketika berkomunikasi.

Menurut Schutz (dalam Hidayati : 2016) keseluruhan tindakan manusia dapat dilihat 
melalui dua faktor yaitu :

In order to motive: motif atau tindakan manusia yang mengacu pada masa yang akan datang.

Because motive: motif atau tindakan manusia yang mengacu pada masa lalu.

Tabel 1. Perbedaan In order to motive dan Because motive

\begin{tabular}{l|l} 
In Order to Motive & Because motive \\
\hline Refers to the future & Refers to past experiences \\
Brought by the future action & Brought by the project of the action itself \\
Subjective & Objective \\
\hline
\end{tabular}

Dalam hal ini, Schutz menyatakan bahwa seringkali suatu tindakan dilakukan karena adanya perilaku yang termotivasi. Jika diinterpretasikan ke dalam sebuah contoh kasus seorang pembunuh melakukan pembunuhan karena memiliki motif untuk mengambil uang dari korbannya, kata motif dalam kasus pembunuhan ini memiliki maksud sebagai suatu tindakan yang dilakukan karena keadaan atau tujuan tertentu. Motif yang seperti ini disebut dengan "In order to motive", dimana pembunuh tersebut memiliki motif yang mengacu pada masa depannya. Lalu ada "Because motive" yang jika diinterpretasikan ke dalam satu contoh kasus yang sama, seorang pembunuh termotivasi untuk melakukan tindakannya karena ia tumbuh dalam lingkungan yang seperti itu atau memiliki pengalaman seperti itu di masa kecilnya. Motif seperti ini disebut sebagai "Because motive" karena tindakan tersebut mengacu pada masa lalunya. (Schutz : 2011).

Berdasarkan hasil wawancara dengan ketujuh informan pada penelitian ini, "Because motive" yang dapat peneliti simpulkan adalah: pertama, yaitu dasar pengetahuan mereka terhadap kualitas pendidikan yang terdapar di Belanda. Dimana ketujuh informan ini telah mengetahui bagaimana kualitas pendidikan di Belanda merupakan salah satu yang terbaik di dunia setelah melakukan berbagai survei dan observasi yang intens. Dasar motif tersebut kemudian membentuk makna bahwa berkuliah di Belanda dilakukan sebagai dasar untuk mendapatkan kualitas pendidikan yang lebih baik. Dengan menjalankan studi di Belanda, selain ketujuh informan dapat memperoleh ilmu yang diingkan, mereka juga menghadapi berbagai perbedaan yang terjadi karena seperti yang kita ketahui bahwa jika dilihat segi geografis dan kultural pun sudah berbeda, tentunya akan menemukan sistem pembelajaran yang berbeda juga.

Namun seringkali dengan adanya perbedaan tersebut juga tidak jarang membuat mereka harus beradaptasi dengan lingkungannya yang baru. Namun karena pada tujuan awalnya mereka ingin pola hidup yang lebih teratur dan tertata karena seperti yang kita ketahui bahwa masyarakat di Belanda memiliki pola hidup yang sangat tertata, maka di satu sisi juga mereka menyadari bahwa hal-hal tersebut harus mereka hadapi agar tujuan dan cita-cita yang mereka inginkan dapat tercapai dan terlewati dengan baik.

Dari motif yang dilakukan ketujuh informan, terbentuk pemaknaan studi di Belanda sebagai cara untuk meraih cita-cita yang diinginkan tentunya dengan berbagai pertimbangan yang dilewati sebelumnya. Karena tentunya setiap individu memiliki ekspektasi nya masingmasing dalam meraih cita-cita nya di masa depan. Namun secara keseluruhan ketujuh informan menganggap bahwa adanya keinginan untuk mencontoh masyarakat Belanda yang memiliki pola hidup yang lebih teratur dan tertata akan turut menunjang mereka dalam menggapai citacitanya. Karena para partisipan percaya bahwa terdapat kekuatan dibalik sebuah pola hidup yang teratur dan lebih tertata. Hal inilah yang mencerminkan seseorang dengan kedisiplinannya yang tinggi, seperti halnya masyarakat di Belanda yang memiliki pola hidup yang lebih tertata yang turut memotivasi partisipan untuk senantiasa memulai untuk menanamkan kebiasaan-kebiasaan positif sehingga pola hidup yang lebih teratur tersebut dapat terbentuk secara perlahan

Dengan ini dapat dijelaskan bahwa pengalaman yang dialami oleh mahasiswa undergraduate Indonesia terbagi dalam tiga pengalaman, yaitu: pengalaman komunikasi lintas 
budaya, pengalaman dengan lingkungan, pengalaman dengan diri sendiri, serta pemaknaan yang dialami mereka dengan model tipifikasi yang ditemukan beberapa tipe dari berbagai aspek, berikut tipe-tipe yang peneliti dapatkan:

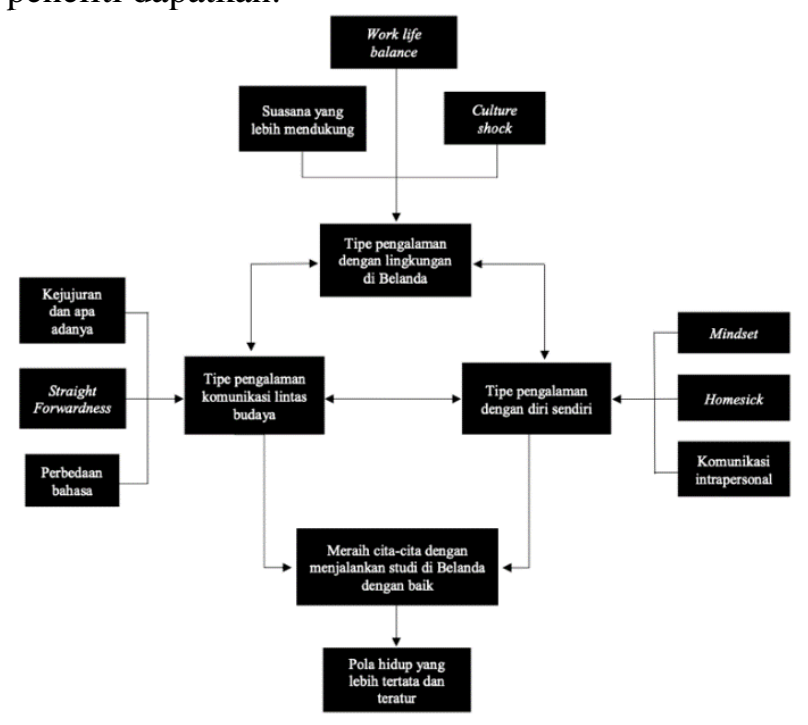

Gambar 4. Model Tipikasi Pengalaman Komunikasi Lintas Budaya Mahasiswa Undergraduate Indonesia di Belanda

\section{Kesimpulan}

Berdasarkan pembahasan dalam penelitian ini, peneliti menyimpulkan beberapa hasil penelitian sebagai berikut:

1. Berdasarkan hasil penelitian dan pembahasan bahwa pengalaman yang dialami oleh mahasiswa undergraduate Indonesia terbagi dalam tiga pengalaman, yaitu: pengalaman komunikasi lintas budaya yang berisikan tentang straight forwardness, kejujuran atau apa adanya, dan perbedaan bahasa. Lalu pada tipe pengalaman dengan lingkungan di Belanda berisikan tentang suasana yang lebih tertata dan mendukung, work life balance, serta culture shock. Kemudian pada tipe pengalaman dengan diri sendiri mencakup beberapa hal yaitu adanya proses komunikasi intrapersonal, perasaan homesick, serta mindset sebagai dasar akan segala sesuatu.

2. Adanya makna yang terbentuk dari mahasiswa undergraduate Indonesia dalam menjalankan proses studi di Belanda sebagai cara untuk meraih cita-cita yang diinginkan tentunya dengan berbagai pertimbangan yang dilewati sebelumnya. Karena tentunya setiap individu memiliki ekspektasi nya masing-masing dalam meraih cita-cita nya di masa depan. Namun secara keseluruhan ketujuh informan memaknai bahwa adanya pola hidup yang lebih teratur dan tertata dari masyarakat Belanda merupakan sebuah faktor pendorong bagi mereka dalam turut menunjang cita-cita yang akan dicapai oleh mereka.

\section{E. Saran}

\section{Saran Teoritis}

Bagi peneliti selanjutnya, disarankan untuk melanjutkan penelitian ini dengan melihat dari segi pengalaman mahasiswa yang sudah lulus dari negara yang dipilih dalam studinya. Pengambilan subjek yang lebih banyak dan agar tipikasi dapat lebih beragam. Juga adanya pemilihan objek pada penelitian, seperti misalnya negara lain dengan keunikannya berbeda.

\section{Saran Praktis}

Berdasarkan hasil penelitian, diharapkan agar subjek untuk lebih mengeksplor lagi dengan negara Belanda agar dapat lebih memahami bagaimana gaya berbicara dan bagaimana kebudayaannya secara mendalam 


\section{Acknowledge}

Dengan ini peneliti berterima kasih kepada dosen pembimbing (Erik Setiawan S.Sos., M.I.Kom), para narasumber; tujuh mahasiswa undergraduate Indonesia di Belanda, dua warga Belanda, dan seluruh pihak yang telah turut serta mendukung dan membantu penulis dalam memberikan data maupun informasi sehingga penelitian ini dapat berlangsung dan selesai dengan baik.

\section{Daftar Pustaka}

[1] Adler, P. S. 2013. The transitional experience: An alternative view of culture shock. Journal of Humanistic Psychology, 15(4), 13-23.

[2] Cangara, Hafied, 2015. Pengantar Ilmu Komunikasi (Edisi Kedua), Jakarta: Raja Grafindo Persada,

[3] Creswell, J. W. 2013. Qualitative Inquiry and Research Design Choosing Among Five Approaches (3rd Ed). Thousand Oaks, CA: Sage Publications.

[4] Griffin, Em. 2006. A First Look at Communication Theory Sixth Edition. New York: McGraw- Hill

[5] Gudykunst, William B. \& Young Yun Kim. 1997. Communicating with Strangers an Approach to Intercultural Communication Third Edition. New York: McGraw-Hill

[6] Hidayati, Nurul. 2016. Pengaruh Kepuasan Kerja Dan Stress Kerja Terhadap Turnover Intention Karyawan Bag. Marketing PT. Wahana Sahabat Utama, Vol. 11. No. 12016

[7] Institute of International Education. 2016. New International Student Enrollment, 2005/06-2015/16. Open Doors Report on International Educational Exchange. Retrieved from http://www.iie.org/opendoors. Diakses pada tanggal 17 Oktober 2020 pukul 18.32

[8] Jenkins, Viktoria dalam Education in the Netherlands https://wenr.wes.org/2018/12/education-in-the-netherlands diakses pada tanggal 7 Desember 2020 pukul 09.22

[9] Kriyantono, Rachmat. 2016. Teknik Praktis Riset Komunikasi. Jakarta : Kencana Prenada Media Group.

[10] Kuswarno, Engkus. 2009. Metodologi Penelitian Komunikasi Fenomenologi: Kosepsi, Pedoman dan Contoh Penelitiannya. Bandung : Widya Padjadjaran.

[11] Moleong, Lexi J. 2007. Metodologi Penelitian Kualitatif. Bandung: PT Remaja Offset

[12] Morgan, Debra A. 2019. Learning in liminality. Student experiences of learning during a nursing study abroad journey: A hermeneutic phenomenological research study.

[13] Mulyana, Deddy \& Jalaludin Rakhmat. 2003. Komunikasi Antar Budaya. Bandung: Remaja Rosda Karya

[14] Niam, E,K. 2009. Koping Terhadap Stres Pada Mahasiswa Luar Jawa Yang Mengalami Culture Shock Di Universitas Muhammadiyah Surakarta. Indigenous, Jurnal Ilmiah Berkala Psikologi, Vol 11 No, 1

[15] Nurtyasrini, Sarah dan Hanny Hafiar. 2016. "Pengalaman Komunikasi Pemulung Tentang Pemeliharaan Kesehatan Diri dan Lingkungan di TPA Bantar Gebang" dalam Jurnal Kajian Komunikasi. Vol 4, No 2 (222)

[16] OECD (2017) Education at Glance pada Learn Like Dutch https://learnlikethedutch.com/international-research/ diakses pada tanggal 7 Desember 2020 pukul 11.44 
[17] Sendjaja, Djuarsa. 2002. Teori Komunikasi. Jakarta : Pusat Penerbitan Universitas Terbuka

[18] Schutz, A. 2011. "Collected Papers V. Phenomenology and the Social Sciences". In L. Embree (Ed.), Springer (5th ed.)

[19] Smith, J.A. and Eatough, V. 2017. Interpretative Phenomenological Analysis.

[20] Smith, R. A., \& Khawaja, N. G. 2011. A review of the acculturation experiences of international students. International Journal of Intercultural Relations, 35(6), 699-713.

[21] Sugiyono. 2014. Metode Penelitian Pendidikan Pendekatan Kuantitatif, Kualitatif, dan R\&D. Bandung: Alfabeta.litt

[22] Sugiyono. 2017. Metode Penelitian Pendidikan (Pendekatan Kuantitatif, Kualitatif dan R\&D). Penerbit CV. Alfabeta: Bandung

[23] Sukmadinata, Nana Syaodih. 2011. "Metode Penelitian Pendidikan”. Bandung: Remaja Rosadakarya 